\title{
Influência do horário de colheita sobre o rendimento e composição do óleo essencial de erva-cidreira brasileira [Lippia alba (Mill.) N. E. Br.]
}

\author{
EHLERT, P.A.D.'; MING, L.C.'; MARQUES, M.O.M.'; FENANDES, D.M.'; ROCHA, W.A.'; LUZ, J.M.Q. ${ }^{*}$; \\ SILVA, R.F. ${ }^{2}$ \\ ${ }^{1}$ UNESP-FCA, Fazenda Lageado, C. P. 237, 18.610-307 Botucatu-SP; ${ }^{2}$ UFU-ICIAG, Bloco 2E, Campus \\ Umuarama, 38.499-902 Uberlândia-MG, *jmagno@umuarama.ufu.br
}

\begin{abstract}
RESUMO: Este trabalho teve como objetivo verificar se o horário de colheita da erva-cidreira brasileira [Lippia alba (Mill.) N. E. Br.], fenotipo carvona-limoneno, tem influência sobre a produção de massa foliar, rendimento e composição do óleo essencial. Foram avaliados cinco horários de colheita quando a cultura estava com 145 dias desde o transplante: 8:00, 10:00, 12:00, 14:00 e 16:00 h com cinco repetições, distribuídos em blocos casualizados. 0 experimento foi conduzido na Fazenda Experimental Lageado da FCA-UNESP/Botucatu no Setor de Horticultura do Departamento de Produção Vegetal. A colheita foi realizada a 15 $\mathrm{cm}$ da superfície do solo e o óleo essencial obtido através de hidrodestilação, em aparelho tipo Clevenger. Levou-se em consideração os fatores agronômicos e o rendimento obtido por hidrodestilação. O óleo essencial foi analisado em cromatógrafo gasoso acoplado a espectrômetro de massas (CG/EM). Os resultados foram submetidos à análise de variância (Teste F) e as médias comparadas pelo teste de Tukey. Não houve diferença estatística para produção de massa foliar, teor de óleo essencial e produtividade de óleo essencial em massa fresca e seca. No entanto, entre os compostos majoritários do óleo essencial das folhas, carvona e limoneno, a melhor produtividade de carvona foi obtida às 10:00 h, em matéria fresca $(2,050$ $\left.\mathrm{L} \mathrm{ha}{ }^{-1}\right)$ e em matéria seca $\left(2,068 \mathrm{~L} \mathrm{ha}^{-1}\right)$, e para o limoneno às 16:00 h, em matéria fresca $(1,068$ $\left.L \mathrm{ha}^{-1}\right)$ e em matéria seca $\left(1,060 \mathrm{~L} \mathrm{ha}^{-1}\right)$.
\end{abstract}

Palavras-chave: Lippia alba, metabolismo secundário, horário de colheita, óleo essencial

ABSTRACT: Influence of harvest time on the yield and composition of essential oil from the Brazilian "erva-cidreira" [Lippia alba (Mill.) N. E. Br.]. This study aimed to verify whether the harvest time of the "Brazilian erva-cidreira" [Lippia alba (Mill.) N. E. Br.], limonene-carvone chemotype, influences leaf mass production and essential oil yield and composition. Five different harvest times were evaluated at 145 days after transplanting: 8:00, 10:00, 12:00, 14:00 and 16:00, with five replicates, distributed in randomized blocks. The experiment was carried out at Lageado Experimental Farm of the School of Agronomical Sciences FCA-UNESP/Botucatu, Horticulture Sector, Department of Plant Production. Harvest was conducted from $15 \mathrm{~cm}$ above the soil surface and essential oil was obtained through steam distillation in a Clevenger-type apparatus. Both the agronomical factors and the yield obtained through steam distillation were considered. The essential oil was analyzed in a gas chromatographer coupled to a mass spectrometer (GC/MS). Results were subjected to analysis of variance ( $F$ Test) and means were compared according to Tukey's test. There was no statistical difference for leaf mass production, essential oil content and essential oil yield in fresh and dry matter. However, considering the major essential oil compounds, carvone and limonene, the best yield was obtained at 10:00 for carvone in fresh $\left(2050 \mathrm{~L} \mathrm{ha}^{-1}\right)$ and dry matter $\left(2068 \mathrm{~L} \mathrm{ha}^{-1}\right)$, and at 16:00 for limonene in fresh $\left(1068 \mathrm{~L} \mathrm{ha}^{-1}\right)$ and dry matter $\left(1060 \mathrm{~L} \mathrm{ha}^{-1}\right)$.

Key words: Lippia alba, secondary metabolism, harvest time, essential oil

\section{INTRODUÇÃO}

Os óleos essenciais são líquidos oleosos voláteis dotados de aroma forte e quase sempre agradável, proveniente do metabolismo secundário
(Silva \& Casali, 2000).

O uso dos óleos essenciais na indústria farmacêutica fundamenta-se nas suas propriedades

Recebido para publicação em 07/05/2009

Aceito para publicação em 24/05/2012

Rev. Bras. PI. Med., Botucatu, v.15, n.1, p.72-77, 2013. 
analgésicas, desinfetantes e antissépticas (Saito \& Scramim, 2000).

As plantas medicinais, como qualquer outra cultura, necessitam de diversas técnicas de cultivo, colheita e pós-colheita, a fim de determinar métodos que proporcionem, concomitantemente, maior acúmulo de biomassa e de constituintes químicos de interesse.

Lippia alba (Mill.) N.E.Br., pertencente à família Verbenaceae, é originária das Américas do Sul e Central (Gomes, 1993). Popularmente é conhecida como: erva-cidreira, erva-cidreira brasileira, erva-cidreira-do-campo, falsa-melissa, alecrim-do-campo, alecrim-selvagem, cidreirabrava, salva (Corrêa Junior et al., 1991).

Suas folhas contêm óleo essencial, sendo que a composição varia de acordo com a base genética e o local de cultivo. Testes histoquímicos realizados em folhas de $L$. alba, provenientes do Jardim Botânico do Rio de Janeiro indicaram que o óleo essencial está presente nos tricomas glandulares e tectores em todo mesofilo no parênquima da nervura principal e ao redor do sistema vascular da nervura (Ventrella, 2000 \& Santos-Mendes, 2001).

Matos (1998) relata que existem, no Nordeste, três tipos de Lippia alba, caracterizados pelos constituintes químicos de seus óleos essenciais, sendo os de elevado teor de citral e mirceno, o tipo 1; de citral e limoneno, o tipo 2 e de carvona e limoneno, o tipo 3.

As indústrias farmacêuticas e de aromas, utilizam a carvona em diversos produtos como: creme dental, anti-séptico bucal, pão, picles, condimentos e bebidas. A carvona apresenta ainda atividade anti-séptica, bactericida e antifúngica (Antunes, 2005).

O limoneno é largamente empregado para odorizar cosméticos, sabonetes e na indústria de alimentos e remédios. Outro uso importante é na preparação de óleos essenciais artificiais do tipo "citrus". Usado ainda como agente dispersante e solvente industrial (Júnior \& Pastore, 2007).

Ecologicamente, uma planta emite determinadas substâncias aromáticas para fins de atração de polinizadores, dispersão de sementes, defesa contra predadores e proteção contra raios UV ou perda excessiva de água por evapotranspiração, supostamente, durante a ocorrência desses fenômenos a concentração dos óleos essenciais é maior; e este seria o horário mais apropriado para a colheita do material vegetal (Jakiemiu, 2008). Nagao (2003) recomenda a colheita de plantas aromáticas no período da manhã. No entanto, os ciclos circadianos e sazonais podem influenciar na composição dos constituintes dos óleos essenciais, particularmente para cada espécie (Gobbo-Neto \& Lopes, 2007).

O objetivo desta pesquisa foi determinar para o fenótipo carvona-limoneno da Lippia alba o horário de colheita ideal em função da produção da massa foliar, do óleo essencial e na produção de carvona e limoneno.

\section{MATERIAL E MÉTODOS}

O estudo foi implantado na Fazenda Experimental Lageado, pertencente à Faculdade de Ciências Agronômicas da UNESP - Campus Botucatu, e as análises laboratoriais referentes à investigação fitoquímica realizadas: no Departamento de Horticultura da UNESP, no Laboratório de Produtos Naturais do Centro de Pesquisa de Recursos Genéticos Vegetais do Instituto Agronômico de Campinas, e na Faculdade de Engenharia de Alimentos (FEA/UNICAMP).

A fazenda está localizada no município de Botucatu/SP, situada entre os paralelos $22^{\circ} 30^{\prime}$ a $23^{\circ} 05^{\prime}$ de latitude Sul e os meridianos $48^{\circ} 15^{\prime}$ a $48^{\circ}$ 52 ' de longitude W Gr e altitude média de $830 \mathrm{~m}$. Seu clima é classificado, segundo Köppen (1948), como mesotérmico de inverno seco (Cwb), com temperatura média anual de $19,4^{\circ} \mathrm{C}$ e precipitação pluviométrica média anual de $1314 \mathrm{~mm}$.

O solo onde o experimento foi instalado foi classificado como latossolo vermelho escuro e suas características químicas, analisadas pelo Departamento de Recursos Naturais/Setor de Ciência do Solo (FCA/UNESP-Botucatu/SP) estão apresentadas na Tabela 1.

Foram utilizadas mudas de erva-cidreira -

TABELA 1. Características químicas do solo coletado, antes da instalação do experimento, na Fazenda Experimental Lageado (análise realizada no Departamento de Recursos Naturais/Setor Ciência do Solo) - FCA/ UNESP, nas profundidades de 0 a $20 \mathrm{~cm}$ (amostra 1) e de 20 a $40 \mathrm{~cm}$ (amostra 2). Botucatu-SP, 2000.

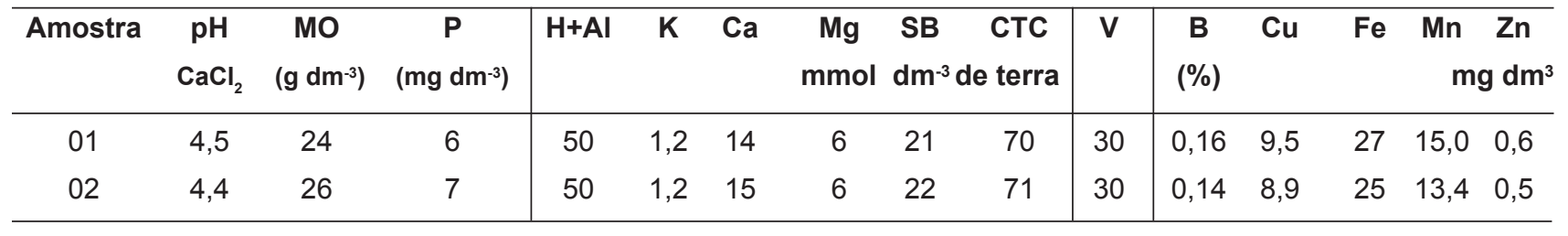

Rev. Bras. PI. Med., Botucatu, v.15, n.1, p.72-77, 2013. 
Lippia alba (Mill.) N. E. Br. (família Verbenaceae), fenotipo limoneno-carvona, obtidas a partir de plantas matrizes fornecidas pela Universidade Federal do Ceará, as quais foram multiplicadas vegetativamente na Fazenda Experimental Lageado (UNESP - Botucatu) até atingir o número necessário de mudas para a instalação do experimento. A referida espécie se encontra catalogada no Herbário Prisco de Bezerra do Centro de Ciências Agrárias, da Universidade Federal do Ceará, sob o o 24.149.

As mudas foram obtidas a partir de estacas sadias de L. alba. As estacas com $20 \mathrm{~cm}$ de comprimento foram colocadas para enraizar em bandejas de isopor de 72 células, tendo como substrato uma mistura de solo e esterco bovino curtido, na proporção de $4: 1$. O transplantio foi realizado após 60 dias.

O delineamento experimental utilizado foi em blocos ao acaso, com cinco tratamentos de horários de colheita: 8:00 (T1), 10:00 (T2), 12:00 (T3), 14:00 (T4) e 16:00 (T5) horas) e cinco repetições. Cada repetição foi constituída de uma parcela com 30 plantas espaçadas de 1,0 m entre linhas e 0,70 m entre plantas, sendo cinco linhas com seis plantas. As 12 plantas centrais foram consideradas as plantas úteis da parcela. Durante o experimento foram realizadas capinas para a eliminação das plantas daninhas.

Os dados referentes às variáveis: produção de massa foliar, rendimento e composição dos óleos essenciais foram submetidos à análise de variância e suas médias comparadas através do teste Tukey para ambos os experimentos. O programa estatístico utilizado foi o SANEST.

Iniciou-se o preparo da área com dois meses antes do plantio com a utilização do arado e grade intermediária para retirar do local resíduo de material de outras culturas e incorporar o que restou destas que estavam presentes na área. Posteriormente, utilizou-se o sulcador para a aplicação de termofosfato. Os sulcos foram fechados deixando a área em descanso. A calagem foi realizada com calcário dolomítico aos 30 dias antes do plantio a fim de elevar a saturação de bases a $60 \%$. Quinze dias antes do plantio aplicou-se a matéria orgânica e, com 10 dias de antecedência, aplicou-se o sulfato de potássio $\left(50 \mathrm{~kg} \mathrm{ha}^{-1}\right)$ sendo o restante $\left(30 \mathrm{~kg} \mathrm{ha}^{-1}\right)$ aplicado em cobertura 20 dias após o plantio.

Para a adubação de plantio utilizaram-se como fonte de nitrogênio, fósforo e potássio os seguintes produtos: 40 ton ha-1 de esterco de curral curtido, $120 \mathrm{~kg} \mathrm{ha}^{-1}$ de termofosfato e $80 \mathrm{~kg} \mathrm{ha}^{-1} \mathrm{de}$ sulfato de potássio, respectivamente. A irrigação, quando necessária, foi feita através do sistema de irrigação por gotejamento.

Aos 145 dias foi realizada a colheita cortando-se as 12 plantas centrais da parcela a 15 $\mathrm{cm}$ do solo, em intervalos de 2:00 h cada colheita. As plantas foram acondicionadas em sacos plásticos e levadas até o laboratório. No laboratório estas foram pesadas (peso fresco) e, logo em seguida, retiram-se 3 amostras de $20 \mathrm{~g}$ de folhas, de cada bloco, para se determinar à umidade do material, as quais foram colocadas para secar em estufa a $105^{\circ} \mathrm{C}$ por 24 horas.

O restante do material foi separado em caule, folhas e inflorescência e novamente pesado, sendo que das folhas retirou-se uma amostra de $200 \mathrm{~g}$ por parcela para a extração do óleo essencial através de hidrodestilação em aparelho Clevenger por período de 150 minutos. Após separação das fases (óleo essencial/água) o óleo essencial foi armazenado em vidro de cor âmbar, com tampa e estocado em freezer $\left(-5^{\circ} \mathrm{C}\right)$ até o momento da análise de sua composição química. O restante das folhas, caule e inflorescência foram colocados para secar a $40^{\circ} \mathrm{C}$ por aproximadamente três dias. Não ocorreu extração de óleo de caule e inflorescência, pois nestas partes da planta as quantidades deste componente são insignificantes.

As variáveis analisadas foram:

-teor de umidade $(\%) \mathrm{U}=(\mathrm{PI}-\mathrm{PF}) / \mathrm{PIX} 100$,

onde PI é o peso inicial e PF peso final;

-massa foliar de cada parcela, obtida através da pesagem individual do material fresco de cada parte de cada planta: caule, folha e inflorescência em balança de 0,01 $\mathrm{g}$ de precisão. Os valores foram convertidos para 1 ha de área cultivada em matéria seca. Os resultados em peso seco provieram da seguinte fórmula (MATTOS, 2000): $M S=M V-(M V \times U \%)$, onde: $M S$ = matéria seca, $\mathrm{MV}=$ matéria verde e $\mathrm{U} \%=$ teor de umidade;

-rendimento do óleo essencial foi obtido através da seguinte expressão: Rendimento $=\mathrm{v}(\mathrm{mL})$ I m (g) x 100; onde: v= volume de óleo essencial extraído e $\mathrm{m}=$ matéria fresca. Os dados obtidos em $\left(\mathrm{mL} / 12\right.$ plantas) foram transformados para $\mathrm{L} \mathrm{ha}^{-1}$. Para transformar essa variável determinou-se a densidade $\left(20^{\circ} \mathrm{C}\right)$ do óleo essencial, em aparelho que mede a densidade e a gravidade específica (Marca Mettler, modelo DA - 310). Foram utilizadas duas amostras de $3 \mathrm{~mL}$ para que o aparelho pudesse efetuar a leitura e a partir destas foi estimada à média aritmética das duas amostras dando 0,927335 de densidade.

A análise da composição química do óleo essencial foi conduzida em cromatógrafo a gás acoplado a espectrômetro de massas (CG-EM Shimadzu, QP 5000), dotado de coluna capilar de sílica fundida DB-5 (30 m x 0,25 mm x $0,25 \mu \mathrm{m}$, J\&W Co.), hélio como gás de arraste $(1,7$ $\mathrm{mL} \mathrm{min}^{-1}$ ), split $1 / 30$, injetor e detector a $240^{\circ} \mathrm{C}$ e $230^{\circ} \mathrm{C}$ respectivamente, com temperatura do

Rev. Bras. PI. Med., Botucatu, v.15, n.1, p.72-77, 2013. 
forno de $50^{\circ} \mathrm{C}$ por $5 \mathrm{~min}$ isotémico, seguido de rampa de temperatura de $5^{\circ} \mathrm{C} \mathrm{min}^{-1}$ até $280^{\circ} \mathrm{C}$. A identificação dos constituintes químicos foi obtida por comparação dos espectros de massas das substâncias com banco do sistema CG/EM como NIST 69 e literatura (McLafferty \& Stanffer, 1989); índice de retenção de Kovats (Adams, 2007) e coinjeções dos padrões de carvona e limoneno. Esta fase do trabalho foi desenvolvida no Laboratório de Produtos Naturais do Centro de Pesquisa e Desenvolvimento de Recursos Genéticos Vegetais do Instituto Agronômico de Campinas (IAC).

$O$ rendimento médio por tratamento do óleo essencial obtido em $\mathrm{L} \mathrm{ha}^{-1}$ foi multiplicado pela porcentagem relativa de cada substância, obtendose assim a produtividade dos compostos majoritários em $L$ ha $^{-1}$ para cada tratamento.

A análise estatística dos principais constituintes foi realizada no SANEST através da análise de variância com as médias comparadas através do teste Tukey.

\section{RESULTADO E DISCUSSÃO}

Não houve diferença estatística para produção de massa foliar, teor de óleo essencial e produtividade de óleo essencial em massa fresca e seca, conforme pode ser observado na Tabela 2.

Os dados obtidos são semelhantes aos encontrados por Ehlert (2000) que, trabalhando com Ocimum gratissium L. em diferentes horários, não observou influência do horário de colheita para produção de massa fresca e seca, bem como no teor de óleo essencial, na região de Pentecostes/CE. Porém, estes, divergem de Silva et al. (1999) que trabalhando com a mesma espécie em Fortaleza/ CE verificaram que o maior teor de óleo essencial ocorre por volta das 12:00 $\mathrm{h}$.

No trabalho de Blank et al., (2005) foi constatado que o teor de óleo essencial de melissa, em função do horário de colheita, não apresentou diferença significativa para os dois horários de colheita (9h e 15h).

Em erva cidreira (Melissa officinalis L.) observou-se que esta deve ser colhida na parte da manhã e suas folhas devem ser secas a $40^{\circ} \mathrm{C}$ para posterior extração do óleo essencial a fim de se obter uma composição que atenda às exigências do mercado internacional (Blank et. al., 2005).

O teor de óleo essencial em couve-cravinho (Porophyllum ruderale) foi maior nas colheitas matinais (Casali, 2003). Pode-se observar que as várias espécies respondem de forma diferente ao horário de colheita; por esta razão, se faz necessário ampliar cada vez mais os estudos com as plantas medicinais para determinar qual o melhor horário de colheita de cada espécie. Assim, o produtor poderá planejar o cultivo da sua cultura de interesse, bem como escolher o composto que lhe convém produzir, aumentando seu lucro e qualidade do produto final.

Com relação à produtividade dos constituintes majoritários, carvona e limoneno, foi observado diferença estatística para a produtividade de carvona em massa fresca e seca a $1 \%$ de probabilidade, e para o limoneno a $5 \%$ de probabilidade (Tabela 3).

Observou-se que a melhor produtividade para a carvona foi obtida às 10:00 $\mathrm{h}$, em massa fresca $\left(2,050 \mathrm{~L} \mathrm{ha}^{-1}\right)$ e seca $\left(2,068 \mathrm{~L} \mathrm{ha} \mathrm{a}^{-1}\right)$ e para o limoneno às 16:00 $\mathrm{h}$; em massa fresca $\left(1,068 \mathrm{~L} \mathrm{ha}^{-1}\right)$ e massa seca $\left(1,060 \mathrm{~L} \mathrm{ha}^{-1}\right)$.

O horário de colheita influenciou na percentagem relativa dos principais compostos. Comparando-se a composição química do óleo essencial verificou-se que a-pineno, trans-cariofileno, germacreno D-4-ol apresentaram traços em todos os horários de colheita. O tricicleno estava presente somente às 8:00 $\mathrm{h}$ e o bulnesol às 8:00 e às 10:00 h (dados não mostrados). A Tabela 4 apresenta a percentagem relativa dos principais constituintes químicos do óleo essencial de $L$. alba em função

TABELA 2. Quadrados médios da produção de massa foliar fresca e seca (ton ha-1), teor de óleo essencial em massa fresca e seca $(\%)$ e produtividade de óleo essencial $\left(L \mathrm{ha}^{-1}\right)$, em função do horário de colheita. UNESP/ Botucatu-SP, 2001-2002.

\begin{tabular}{|c|c|c|c|c|c|c|c|}
\hline $\begin{array}{l}\text { Causas } \\
\text { da } \\
\text { variação }\end{array}$ & G.L. & $\begin{array}{c}\text { Massa } \\
\text { foliar fresca } \\
(\text { ton ha-1) }\end{array}$ & $\begin{array}{l}\text { Massa } \\
\text { foliar seca } \\
\text { (ton há-1) }^{-1}\end{array}$ & $\begin{array}{l}\text { Teor de óleo } \\
\text { essencial }{ }^{1} \\
(\%)\end{array}$ & $\begin{array}{c}\text { Teor de óleo } \\
\text { essencial }{ }^{2} \\
(\%)\end{array}$ & $\begin{array}{l}\text { Produtividade de } \\
\text { óleo essencial } \\
\left.\text { (L há-1 }{ }^{1}\right)\end{array}$ & $\begin{array}{c}\text { Produtividadede } \\
\text { óleo essencial } \\
\left.\text { (L há }^{-1}\right)\end{array}$ \\
\hline Bloco & 4 & & & & & & \\
\hline Horário & 4 & $0,01123^{\text {ns }}$ & $0,00275^{\text {ns }}$ & $0,01823^{\text {ns }}$ & $0,25692^{\text {ns }}$ & $2,8644539^{\text {ns }}$ & $2,8085802^{\text {ns }}$ \\
\hline Resíduo & 16 & 0,084 & 0,0052 & 0,0070 & 0,104 & 0,999 & 0,989 \\
\hline Total & 24 & & & & & & \\
\hline C.V. & & $26,3 \%$ & $26,2 \%$ & $30,1 \%$ & $29,3 \%$ & $32,8 \%$ & $32,5 \%$ \\
\hline
\end{tabular}

ns - não significativo.

1/Teor de óleo essencial em massa fresca. ${ }^{2 / T e o r ~ d e ~ o ́ l e o ~ e s s e n c i a l ~ e m ~ m a s s a ~ s e c a . ~}$ 
TABELA 3. Produtividade média de carvona e limoneno $\left(L^{h a-1}\right)$ em massa fresca e seca em função dos diferentes horários de colheita.UNESP/Botucatu-SP, 2001-2002.

\begin{tabular}{ccccc}
\hline $\begin{array}{c}\text { Horários de } \\
\text { colheita }(\mathrm{h})\end{array}$ & $\begin{array}{c}\text { Produtividade de } \\
\text { carvona }^{1}\left(\mathrm{~L} \mathrm{ha}^{-1}\right)\end{array}$ & $\begin{array}{c}\text { Produtividade de } \\
\text { limoneno }\left(\mathrm{L} \mathrm{ha} \mathrm{C}^{-1}\right)\end{array}$ & $\begin{array}{c}\text { Produtividade de } \\
\text { carvona }^{2}\left(\mathrm{~L} \mathrm{ha}^{-1}\right)\end{array}$ & $\begin{array}{c}\text { Produtividade de } \\
\text { limoneno }^{2}\left(\mathrm{~L} \mathrm{ha}^{-1}\right)\end{array}$ \\
\hline $8: 00$ & $0,874 \mathrm{BC}$ & $0,384 \mathrm{~B}$ & $0,884 \mathrm{BC}$ & $0,392 \mathrm{~B}$ \\
$10: 00$ & $2,050 \mathrm{~A}$ & $0,636 \mathrm{AB}$ & $2,068 \mathrm{~A}$ & $0,686 \mathrm{AB}$ \\
$12: 00$ & $0,742 \mathrm{C}$ & $0,676 \mathrm{AB}$ & $0,746 \mathrm{C}$ & $0,680 \mathrm{AB}$ \\
$14: 00$ & $1,922 \mathrm{AB}$ & $0,914 \mathrm{AB}$ & $1,930 \mathrm{AB}$ & $0,918 \mathrm{AB}$ \\
$16: 00$ & $1,90 \mathrm{AB}$ & $1,068 \mathrm{~A}$ & $1,896 \mathrm{AB}$ & $1,060 \mathrm{~A}$ \\
\hline
\end{tabular}

Médias seguidas da mesma letra na coluna não diferem significativamente ao nível de $1 \%$ de probabilidade pelo teste de Tukey para a carvona e $5 \%$ de probabilidade para o limoneno.

${ }_{1 / \text { Produtividade em massa fresca. }}$

2/Produtividade em massa seca.

TABELA 4. Percentagem relativa (\%) dos principais componentes do óleo essencial de folhas de $L$. alba em função dos diferentes horários de colheita em massa fresca. UNESP/Botucatu - SP, 2001-2002.

\begin{tabular}{cccccccc}
\hline \multirow{2}{*}{$\begin{array}{c}\text { Horários de } \\
\text { colheita }(\mathrm{h})\end{array}$} & \multicolumn{7}{c}{ Percentagem relativa $(\%)$} \\
\cline { 2 - 7 } & Carvona & Limoneno & Sabineno & Y-terpineno & Linalol & Elemol & Guaiol \\
\hline 8:00 & $49,48 \mathrm{~A}$ & $28,66 \mathrm{~A}$ & $2,25 \mathrm{~A}$ & $0,96 \mathrm{~B}$ & $1,30 \mathrm{~B}$ & $3,62 \mathrm{~A}$ & $0,56 \mathrm{~A}$ \\
$10: 00$ & $51,41 \mathrm{~A}$ & $20,45 \mathrm{~B}$ & $1,38 \mathrm{~B}$ & $0,91 \mathrm{~B}$ & $1,25 \mathrm{~B}$ & $4,52 \mathrm{~A}$ & $0,42 \mathrm{~A}$ \\
$12: 00$ & $26,66 \mathrm{~B}$ & $23,05 \mathrm{AB}$ & $1,81 \mathrm{AB}$ & $1,29 \mathrm{~A}$ & $1,72 \mathrm{~A}$ & $3,27 \mathrm{~A}$ & $0,48 \mathrm{~A}$ \\
$14: 00$ & $54,91 \mathrm{~A}$ & $25,85 \mathrm{AB}$ & $1,91 \mathrm{AB}$ & $0,94 \mathrm{~B}$ & $1,31 \mathrm{~B}$ & $4,90 \mathrm{~A}$ & $0,23 \mathrm{~A}$ \\
$16: 00$ & $51,93 \mathrm{~A}$ & $27,85 \mathrm{~A}$ & $2,09 \mathrm{~A}$ & $0,80 \mathrm{~B}$ & $1,18 \mathrm{~B}$ & $5,08 \mathrm{~A}$ & $0,53 \mathrm{~A}$ \\
\hline Média & 46,88 & 25,17 & 1,89 & 0,98 & 1,35 & 4,28 & 0,44 \\
\hline DMS & 19,36 & 5,77 & 0,55 & 0,21 & 0,24 & 1,97 & 0,37 \\
\hline
\end{tabular}

Médias seguidas de mesma letra na coluna não diferem estatisticamente entre si ao nível de $5 \%$ de probabilidade pelo teste Tukey.

dos diferentes horários de colheita.

Não houve alterações significativas nos teores de elemol e guaiol dentro dos períodos avaliados, porém, para os teores de carvona, limoneno, sabineno, g-terpineno e linalol observaramse diferenças estatísticas significativas (Tabela 4). Os constituintes g-terpineno e linalol apresentaram o maiores teores às $12: 00 \mathrm{~h}$, enquanto que nesse mesmo horário a carvona apresentou o menor teor. Limoneno e sabineno apresentaram comportamento estatístico similar, onde os menores teores observados foram às 10:00 h, mas não se diferenciando estatísticamente dos teores obtidos às 12:00 $\mathrm{h}$ e 14:00h.

Os óleos essenciais são constituídos de uma mistura de várias substâncias, sendo que os teores de cada uma depende de fatores ambientais onde a planta foi cultivada (Andrade \& Casali, 1999).

Pode-se observar que o cultivo de plantas medicinais ainda necessita de vários estudos e, dentre eles, está o horário e a época de colheita. No presente trabalho concluiu-se que não ocorreu diferença estatística na produção de massa foliar e rendimento de óleo essencial. Porém, se constatou alterações nos teores dos constituintes químicos principais em função dos diferentes horários de colheita. A menor produtividade de carvona foi observada quando a planta foi colhida às $12: 00 \mathrm{~h}$ e de limoneno às 10:00 $\mathrm{h}$.

\section{REFERÊNCIA}

ADAMS, R. P. Identification of essential oil components by gas chromatography/mass spectroscopy. Carol Stream: Allured Publishing Corporation, 2007. 469p.

ANDRADE, F.M.C.; CASALI, L. A. Plantas medicinais e aromáticas: relação com o ambiente, colheita e metabolismo secundário. Viçosa: UFV - Departamento de Fitotecnia, 1999. 139p.

ANTUNES, O. A. C. Interfaces com a indústria. Química Nova, v. 28, suplemento, S64-S75, 2005.

BLANK, A.F.; FONTES, S. M.; CARVALHO-FILHO, J. L.S.; ALVES, P. B.; SILVA-MANN, R.; MENDONÇA, M. C.; ARRIGONI-BLANK, M. F.; RODRIGUES, M. O. Influência do horário de colheita e secagem de folhas no óleo essencial de melissa (Melissa officinalis L.) cultivada em dois ambientes. Revista Brasileira de 
Plantas Medicinais, v.8, n.1, p.73-8, 2005. Disponível em: http://www.ibb.unesp.br/ servicos/publicacoes/rbpm/ pdf/resumo25.pdf. Acesso em: 01 abr. 2009.

CASALI, W.V.D. Plantas medicinais: o potencial da nossa flora. Millefolium Ervas e temperos. Disponível em: < http: revista.fapemig.Br/11/fitotecnia.html>. Acesso em: 07 set. 2003.

CORRÊA JUNIOR, C.; MINET, L.C.; SCHEFFER, M.C. Cultivo de plantas medicinais, condimentares e aromáticas. Curitiba: EMATER/PR. 162 p. 1991. EHLERT, P.A.D. Aspectos agronômicos da alfavacacravo (Ocimum gratissimum L.). 2000. Dissertação (Mestrado em Agronomia/Fitotecnia) - Universidade Federal do Ceará, Fortaleza, CE, 2000.

FRIGHETTO, N., OLIVEIRA, J.G. Lippia alba (Mill.) N.E. Br. (Verbenaceae) as a Source of Linalol. Journal Essential Oil Research, v.10, p.578-80, 1998. GOBBO-NETO, L.; LOPES, N. P. Plantas medicinais: fatores de influência no conteúdo de metabólitos secundários. Química Nova, v. 30, n.2, p.374-81, 2007. GOMES, E.C. et. al. Constituintes de óleo essencial de Lippia alba (Mill) N.E. Br. (Verbenaceae). Revista Brasileira de Farmácia, v.74, n.2, p.29-32, 1993.

JAKIEMIU, E. A. R. Uma contribuição ao estudo do óleo essencial e do extrato de tomilho (Thymus vulgaris L.). Dissertação de mestrado - Universidade Federal do Paraná, Curitiba, PR, 2008.

JÚNIOR, M. R. M.; PASTORE, G. M. Biotransformação de limoneno: uma revisão das principais rotas metabólicas. Química Nova, v. 30, n. 2, p. 382-87, 2007.

KÖPPEN, W. Climatología: con un estúdio de los climas de la tierra. Mexico: Fondo de Cultura Economica, 1948. 478p.

MATOS, F.J.A. Descrição das plantas medicinais. In Farmácias vivas. 3.ed. Fortaleza: Edições Universidade Federal do Ceará, p.107-8, 1998.

MATOS, F.J.A. et. al. Essential oil composition of two chemotypes of Lippia alba grow in Northeast Brazil. Journal Essential Oil Research, v.8, p.695-8, 1996. McLAFFERTY, F.W.; STANFFER, D.B. Registry of mass espectral data. New York: Willey-Interscience Publishing, 1989. v.1, 1038 p.

NAGAO, E. Práticas de manejo de produção e pós-colheita de erva cidreira (Lippia alba Mill N. E. Br.) quimiotipo II (citral/limoneno), 2003. 82p. Tese (Doutorado em Fitotecnia), Universidade Federal do Ceará, Fortaleza.

PICCAGLIA, R.; MAROTTI, M.; DELLACECCA, V. Effect of planting density and harvest date on yield and chemical composition of Sage oil. Journal Essential Oil Research, v.9, p.187-91, 1997.

PINO, J.A.; ORTEGA, A. Chemical composition of the essential oil of Lippia alba (Mill) N. E. Brown from Cuba, v.4, n.8, p.445-6, 1996.

SAITO, M.L.; SCRAMIM, S. Planta aromáticas e seu uso na agricultura. Jaguariúna: Embrapa Meio Ambiente, 2000. 48p. (Documentos, 20).

SANTOS-MENDES, M.M.F.B.S. Caracterização morfoanatômica, fitoquímica e molecular de 8 formas de Lippia alba (Mill) N. E. Br. ex. Britt e Wilson, cultivadas em Botucatu. 2001. 102p. Tese (Doutorado em Horticultura) - Faculdade de Ciências Agronômicas, Universidade Estadual Paulista, Botucatu.

SILVA, F.; CASALI, V.W.D. Plantas medicinais e aromáticas: pós-colheita e óleos essenciais. Universidade Federal de Viçosa, 2000. 135 p.

SILVA, M.G.V. et al. Chemical variation during daytime of constituents of the essential oil of Ocimum gratissimum leaves. Fitoterapia. v.70, p.32-4, 1999.

TUCKER, A.O.; MACIARELLO, M.J. Volatile leaf oil of the "Licorice Verbena" [Lippia alba (Mill) N. E.Brown ex. Britton and P. Wils. Var. carterae Moldenke] from the North American Herb Trade. Journal Essential Research, v.3, n.11, p.314-6, 1999

VENTRELLA, M.C. Produção de folhas, óleo essencial e anatomia foliar quantitativa de Lippia alba (Mill) N.E.Br. (Verbenaceae) em diferentes níveis de sombreamento e épocas de collheita. 2000. 84p. Tese (Doutorado em Horticultura) - Faculdade de Ciências Agronômicas, Universidade Estadual Paulista, Botucatu. 